\title{
nature
} medicine

\section{Petrifying research?}

With the perpetrators of the anthrax attacks against the United States still at large, a flurry of legislative bills is being rushed through the US Congress with the goal of diminishing the threat of further bioterrorism. Faced with a government that needs to act swiftly to calm a public craving for reassurance (and moreover a government that has to be seen to be doing so), the biomedical research community must actively participate in the crafting of new legislation to ensure that the process of scientific endeavor is not restricted.

The antiterrorism legislation HR 3162, known as the PATRIOT Act, was signed by President Bush on 26 October and is now law. Part of this Act extends the previous biological weapons statute that regulated the transfer of 'select agents' from one facility or person to another. Thirty-six agents are officially listed as select agents: 13 viruses, 7 bacteria, 3 Rickettsiae, 1 fungus and 12 toxins. HR 3162 extends the regulations to now make it an offense for a person to knowingly possess any biological agent, toxin or delivery system of a type or in a quantity that is not justified by bona fide protective research or other peaceful purpose. Importantly, it also restricts certain persons-primarily aliens from countries designated as supporting terrorism-from possessing a select agent.

\section{Waivers}

Some proposed bills go further and would extend the prohibition to all aliens with a non-immigrant visa. It is still unclear how difficult it would be for a foreign student or scientist to work in a US laboratory that has any of the select agents, but all such individuals would at least be required to hold waivers granted only at the discretion of the Secretary of Health and Human Services (HHS). Important questions remain unanswered: On what criteria would waivers be decided? How promptly would they be granted? To what extent would foreign scientists have their backgrounds checked? Other bills propose a background check from the Department of Justice for any individual, regardless of nationality, who intends to handle a select agent.

New amendments and drafts are presented every week, each different with regard to the restriction of alien scientists, registration requirements, penalties imposed and the time to implementation. The intention is to pass a consolidated law by the end of the year.

If procedures to get clearance become more cumbersome they will dissuade foreign students, postdoctoral fellows and established scientists from working in the US or entering into collaborations, even in fields not directly connected to potential agents of bioterrorism. In a country where aliens comprise a substantial proportion of the research workforce (see news page 1261), such measures may impedeeven petrify-the very research that must provide the answers required to diminish the threat of bioterrorism.

Of course, tighter control over the availability of dangerous biological agents is necessary and welcome given the current climate. But undue haste, without sufficient consultation with scientists and civil liberties advocates, may burden the US with new criminal laws that could considerably hamper biomedical research and deny some basic civil rights. And legislation intended to restrict access to agents with potential as bioweapons may have severe repercussions on other areas of biomedical research such as basic virology, microbiology or genetic engineering.

The rush to legislate, the imprecise language and vagueness of some of the provisions are legitimate concerns, but another worry is the possibility that an additional set of regulations not yet defined could dramatically change the way science is conceived and performed. Discussions are underway to try to control and perhaps ban experimentation on the virulence and pathogenicity of biological agents; to define certain scientific information (such as the genome sequence of pathogens) as 'classified'; or simply to limit any and all laboratory equipment that could potentially be used to produce biological weapons.

\section{Key player}

The American Society of Microbiology (ASM) is actively engaged in discussions with and lobbying of Congress to modify the language and the provisions of these new bills. We applaud their efforts to strike the right balance between the need to legislate to increase national security and the necessity to allow science to proceed apace. The ASM represents 42,000 microbiologists but many scientists are unaware of these new legislative drives; those that are aware feel most of Congress' effort is ill-informed and that it will merely hinder efficiency without reducing the threat of bioterrorism. The ASM considers that the best short-term solution would be to pass more general legislation to enable negotiation during the rule-making process. Now is the time for the biomedical research community to make itself heard, not just as an educational authority but also as the key player in fighting the new battle against bioterrorism. 